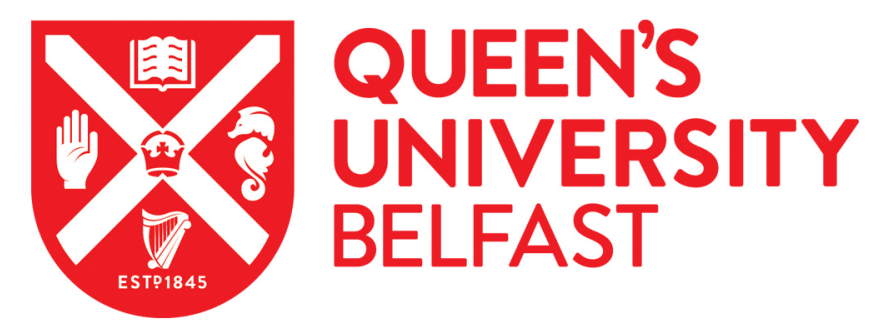

\title{
Simulation of Oil Shale Semi-Coke Particle Cold Transportation in a Spouted Bed Using CPFD Method
}

\author{
Zhang, L., Wang, Z., Wang, Q., Qin, H., \& Xu, X. (2016). Simulation of Oil Shale Semi-Coke Particle Cold \\ Transportation in a Spouted Bed Using CPFD Method. Powder Technology, 301, 360-368. \\ https://doi.org/10.1016/j.powtec.2016.06.012
}

Published in:
Powder Technology

Document Version:

Peer reviewed version

Queen's University Belfast - Research Portal:

Link to publication record in Queen's University Belfast Research Portal

\section{Publisher rights}

Copyright 2016 Elsevier.

This manuscript is made available under a Creative Commons Attribution-NonCommercial-NoDerivs License

(https://creativecommons.org/licenses/by-nc-nd/4.0/), which permits distribution and reproduction for non-commercial purposes, provided the author and source are cited.

\section{General rights}

Copyright for the publications made accessible via the Queen's University Belfast Research Portal is retained by the author(s) and / or other copyright owners and it is a condition of accessing these publications that users recognise and abide by the legal requirements associated with these rights.

\section{Take down policy}

The Research Portal is Queen's institutional repository that provides access to Queen's research output. Every effort has been made to ensure that content in the Research Portal does not infringe any person's rights, or applicable UK laws. If you discover content in the Research Portal that you believe breaches copyright or violates any law, please contact openaccess@qub.ac.uk. 


\title{
Simulation of Oil Shale Semi-Coke Particle Cold Transportation in a Spouted \\ Bed Using CPFD Method
}

\author{
Lidong Zhang, ${ }^{a, b, *}$ Zijia Wanga ${ }^{a}$,ing Wang ${ }^{a}$, Hong Qin a, Xiandong Xü,* \\ a Engineering Research Centre of Oil Shale Comprehensive Utilization, Ministry of Education, Northeast Dianli University, Jilin, \\ Jilin 132012, People's Republic of China \\ b School of Electronics, Electrical Engineering and Computer Science, Queen's University Belfast, Belfast, BT9 5AH, United \\ Kingdom \\ Email address: nedu1015@aliyun.com; (L. Zhang); x.xu@qub.ac.uk (X. Xu). Tel: +44 (0)28 90974480.
}

\begin{abstract}
The spouted bed was widely used due to its good mixing of particles and effective phase transferability between the gas and solid phase. In this paper, the transportation process of particles in a 3D spouted bed was studied using the Computational Particle Fluid Dynamics (CPFD) numerical method. Experiments were conducted to verify the validity of the simulation results. Distributions of the pressure, velocities and particle concentration of transportation devices were investigated. The motion state and characteristics of multiphase flows in the transportation device were demonstrated under various operating conditions. The results showed that a good consistency was obtained between the simulated results and the experimental results. The motion characteristics of the gas-solid two-phase flow in the device was effectively predicted, which could assist the optimal operating condition estimation for the spouted transportation process.
\end{abstract}

Key words: multiphase flows; spouted bed; numerical simulation; experimental study; particle transportation

\section{Introduction}

Due to the rapid particle circulation, rare bubbles production and regular particle distribution, the spouted bed technology $[1,2]$ has been increasingly used in coal or biomass gasification, drying, combustion [3], flue gas desulphurization [4], and particle crushing [5]. The primary difficulty in the spouted bed study is how to obtain accurate flow parameters. A number of modern measurement techniques have been applied to the multiphase flows in the spouted bed, including fiber probe [6,7], capacitance probe [8], laser doppler anemometry [9] and particle image velocimetry [10, 11]. However, owing to the extremely com- 
plex multiphase flow characteristics in the bed, the traditional measurement methods are mostly used for simplified two-dimensional spouted beds. Until now, there is no efficient measurement methods that can fully obtain comprehensive and accurate multiphase flow characteristics in three-dimensional spouted beds [12].

Numerical simulation provides a precious opportunity to understand the motion characteristic of multiphase flows [13, 14]. For spouted beds, simulations can predict the flow state, velocity distribution, pressure distribution and other parameters of the fluidized process. Also, it provides a large amount of data for the study of multiphase flows kinetic characteristics. S. Benyahia, and S. K. Hae et al. [15, 16] used kinetic theory of numerical simulation to investigate the fluidized processes and prove the feasibility of applying numerical simulation to the research of multiphase flows. The computational particle fluid dynamics (CPFD) numerical method is considered to be a more powerful tool for the simulation of large gas-solid two-phase flow system. It has been used for analyzing various gas-solid systems in recent years, considering that its multiphase flow model was developed incorporating dense phase, dilute phase, and packing particles algorithm for reducing computation [17, 18, 19].Q. Wang et al. [20, 21] simulated the gas solid flow in a circulating fluidized bed (CFB) with a loop seal. They investigated the influences of operating parameters, including loop seal aeration rate, fluidized air velocity in the riser, and total bed inventory on the solid circulation characteristics. A. Abbasi et al [22] simulated a fast fluidized bed steam coal gasifier feeding section. F. Fotovat and Y. Liang et al [23, 24] simulated a bubbly biomass-sand fluidized bed. From these results, the validity of CPFD method in modeling of gas-solid flows in complex systems have been extensively demonstrated. It can simulate the gas solid two phase system efficiently and accurately, and we will try to use CPFD method to make overall analysis of larger systems.

In this study, the gas-solid two-phase flow in a cold transportation experimental table was simulated using CPFD numerical schemes. Simulation results were compared with the experimental data. The main contributions of this work are summarized below:

(1) An integrated view of the motion properties of multiphase flow in the spouted bed transportation device was made. According to the simulation results, key characteristics of multiphase flow were analyzed and compared with experimental data. A further insight of the spouted bed transportation process was made. 
(2) A verification of potential feasibility of applying the CPFD method to the prediction of gas-sold system. CPFD was firstly utilized in the spouted bed simulation and validated by experiment. It is proved to be applicable to large gas-solid two-phase flow systems because of its computational speed and reliability.

(3) A foundation for the numerical simulation of next hot transportation process was laid. It provides reference to the research of motion properties in the temperature rising transportation process.

The rest of the paper is organized as follows: Section 2 describes the experimental table and simulation configurations. In Section 3, the simulation results are discussed and compared with the experimental data to investigate the motion properties of multiphase flow in the spouted bed. Finally, conclusions are summarized in Section 4.

\section{Experimental setup and simulation configurations}

\subsection{Experimental setup}

In this paper, all experiments were carried out on the spouted bed cold transportation platform, as shown in Fig. 1. Air was used as the fluidizing gas through the apparatus by an exhaust fan. The air flow rate was regulated by an intelligent vortex flow meter. A screw feeder was used to offer solid feed to the experimental devices. The pressure data was collected from the measurement points in the U-tube manometer. The semi-coke after screening was put into the hopper, and the air was injected into the bed by the blower. The air flow rate was adjusted to the pre-set value obtained from the intelligent vortex flow meter. The semi-coke particles were fed by screw feeder and adjusted to the pre-set mass flow rate. After entering the steady state, the reading of U-tube manometers were recorded. Then the air flow rate or the mass flow rate was changed to complete all setting conditions of experiment. The height of all measurement points is also shown in Fig. 1.

The platform can be used to transport different types of particles. In this paper, semi-coke particles were investigated. The particles were crushed by a standard Taylor sieve and then sieved into bulks with the diameter of $0-5 \mathrm{~mm}$. The true relative density of semi-coke particles is $1200 \mathrm{~kg} / \mathrm{m}^{3}$ and the sphericity of semi-coke particles is 0.6. The diameters distributions of the particles is shown in Table . 
Fig. 1 The cold transportation experimental platform

Table 1 Diameter distributions of the particles

\subsection{Simulation configurations}

As shown in Fig. 2, the simulation model of the cold transportation process was implemented using the CPFD. The detailed simulation parameters are presented in Table. The model was configured to be consistent with the experimental parameters. The grid density was verified by the grid independence experiment, as shown in Table. Then the grid lines on the model surface were tuned to ensure that the simulation area was in strict accordance with the model structure. In order to improve the accuracy of the simulation, the grid density was increased at key parts, including the inlet and outlet of the spray area, and the cyclone separator. The size of the cells for the "fine" case is about $4.8 \times 4.8 \mathrm{~mm}$. The Wen-Yu model in Barracuda is based on single particle drag models plus a dependence on the fluid volume fraction to account for the particle packing and appropriate for dilute systems [25]. In the spouted transportation process, most of the spray area and conveying section are filled with dilute flow [26]. Therefore, the drag coefficients can be extracted based on Wen-Yu model in this simulation. The present work chose $r_{n}=0.3$ and $r_{t}=0.99$ for the wall momentum retention as suggested by Barracuda user manual [25] and the study of Q. Wang [20] and C. Chen [27]. In the simulation process, the air volume and mass flow rate of feeding semi-coke were used as variables referring to the experimental setup. The air flow rates were set to be $70.4 \mathrm{~m}^{3} / \mathrm{h}, 106.2 \mathrm{~m} / \mathrm{h}$, and $141.6 \mathrm{~m}^{3} / \mathrm{h}$, separately. The mass flow rates of feeding semi-coke are $10 \mathrm{~kg} / \mathrm{h}, 15 \mathrm{~kg} / \mathrm{h}$, and $20 \mathrm{~kg} / \mathrm{h}$. The pressure of the empty bed under the three operating conditions were simulated and measured. The simulation time of all working condition was set to be $15 \mathrm{~s}$, and the average data from 5 to $15 \mathrm{~s}$ is employed for further analysis.

Fig. 2 The structure of the cold transportation model

Table 2 Main parameters adopted base line model of the CPFD simulation

Table 3 The influence of the grid number on the pressure of measuring points in the top spray area 


\section{Results and discussion}

\subsection{Pressure distribution}

In order to verify the feasibility of the spouted bed transport process by CPFD method, the pressure data of simulation were compared with the experimental data first under different air and mass flow rates. The results in the empty bed is shown in Fig. 3. It can be seen that the pressure in the area before cyclone uniformly reduced when the mass flow rate increases, and in the cyclone are almost unchanged. The pressure increases when the air flow rate in the empty bed goes up. Meanwhile, as the air flow rate increases, the pressure of the whole system drops significantly. The pressure drop in the empty bed determined by the resistance of device structure will increase as the fluid velocity rises up. In addition, an obvious pressure increase happens in the spray area. The kinetic energy of the airflow decreases significantly when the airflow gets into the spray area from the tubule, without considering local airflow emission. The rest of energy loss caused by airflow emission is converted into static pressure energy.

Fig. 4 Pressure distribution in an empty bed at various air flow rates

Fig. 4 shows pressure distribution with a mass flow rate of feeding semi-coke of $15 \mathrm{~kg} / \mathrm{h}$ at various air flow rates. Compared with the empty bed operation, the pressure drop in all scenarios increase because of the energy consumption of particles transportation process. The drag caused by particles mixing in the spray area also consumes some energy. Thus, the pressure difference between the spray area and the pipeline is less than the empty bed.

Fig. 3 Pressure distribution of various air flow rates with $15 \mathrm{~kg} / \mathrm{h}$ feeding semi-coke

Fig. 5 Pressure distribution of various semi-coke feeding rates with $106.2 \mathrm{~m}^{3} / \mathrm{h}$ air flow rate

Fig. 5 shows the pressure distribution with the air flow rate of $106.2 \mathrm{~m}^{3} / \mathrm{h}$ at various mass flow rates. Since the void volume in the pipeline was increased along with the raising amount of particles, it can be found that the pressure before the spray area was uniformly reduced with the mass flow rate increasing. This phenomenon resulted in the increase of friction resistance between particles and the decrease of pressure. However, changing the mass flow rate has almost no impacts on pressure in the top spray area and the cyclone separator. This indicates that most of the particles in the spray area are in the fluidized state instead 
of transport state at $106.2 \mathrm{~m}^{3} / \mathrm{h}$ air flow rate. Particles suspend in the air flow and the resistance of particles is approximately equal to the bed weight in the fluidized state, and thus the impact of the mass flow rate on the pressure is very small.

Fig. 3, Fig. 4 and Fig. 5 show that the simulation curves are in agreement with the experimental curves. The simulation results are relatively lower than experimental data in the high air flow rate, and the maximum error is about $10 \%$. One of the reason for this phenomenon is that the effect of heat on the fluid viscosity was completely ignored in the simulation process. However, the friction heat generated in the pipeline transportation process and spout process increased as the mass flow rate goes higher than the designed value in practice, which results in the simulation result error. Moreover, the simulation results demonstrate that changing mass flow rate has almost no impacts on the pressure in the top spray area and cyclone separator, but the pressure in the spray area still has a downward trend as the mass flow rate increases. This is because particles with the same characteristics are packed into one group in CPFD method, which reduces the impact of the mass flow rate change on the system in a certain extent, and leads minor pressure distribution change in the simulation results.

\subsection{Velocity distribution}

Particle and flow velocity vector in the top spray area are shown in Fig. 6 and Fig. 7. It can be seen that the movement of particles rise along the central jet, and fall in the near wall annulus area. The fountain area composed of a small amount of little particles at the top of the spray area. The particle velocity distribution in the spray area shows the trend that rises in the central region and falls in the region near the wall. Gas flow experiences rapid deceleration after entering into the spray area until the velocity reduces to about $1.5 \mathrm{~m} / \mathrm{s}$, and the air flow rate will be stable at this velocity until exit the spray area. Above the outlet air flow which does not leave the spray area will incline towards the outlet side. This part of air flow reaches the headpiece of the spray area and goes down when it is away from the outlet side, and back-mixing with the rising air flow.

Fig. 6 Particle velocity vector in the top spray area

Fig. 7 Flow velocity vector in the top spray area 
The particle velocity distribution and flow velocity distribution at various heights are shown in Fig. 8 and Fig. 9. Combined particle velocity vector can be found where particle velocity direction is upward in the central part of the spray area, and downward close to the wall. Due to maximum spouted height difference, heavier particles in the rising state constantly fall in the spouting process. As a result, the bottom of spray area has more falling particles than the upper portion. It can be found in the fluid velocity distribution sectional view that reverse downward movement happens to the air flow in the bottom of the spray area at the vertical direction of the vector map. Since the bottom of the spray area that is close to the wall in parts shows a low pressure when high-speed fluid enters into the spray area, part of air will turn back to replenish around the inlet of spray area due to pressure difference.

Fig. 8 Particle velocity distribution at various heights of the spouted area

Fig. 9 Flow velocity distribution at various heights of the spouted area

\subsection{Concentration distribution}

The particle concentration distribution at various heights are shown in Fig. 10. It can be seen that the concentration distribution in the spray area is high near the wall and low in the central region. As the height increases, the particle concentration decreases gradually. With the progress spouted process, large particles continuously fall from spouted flow, which indicates the screening function of the spouted bed.

Fig. 10 Particle concentration distribution at various heights

Fig. 11 shows particles spouted transport situation at various air flow rates up to 15 seconds. Due to fewer large-diameter particles, the particles whose diameters are larger than $1 \mathrm{~mm}$ becomes red to clearly observe the case of large-diameter particles. It can be seen that at $70.4 \mathrm{~m}^{3} / \mathrm{h}$ air flow rate, almost all particles stay in the spray area a long time, and large-diameter particles will drop out from the inlet of the spray area. At the air flow rate of $106.2 \mathrm{~m}^{3} / \mathrm{h}$, particles whose diameter are below $0.5 \mathrm{~mm}$ are quickly conveyed away from the spray area. The rest of particles remain in the spray area to continue the spouting cycle. At the air flow rate of $141.6 \mathrm{~m}^{3} / \mathrm{h}$, only large-diameter particles can maintain the spouted state, and most particles will soon be transported out of the spray area.

Fig. 11 Particles spouted transport situation at various air flow rates 
The residence time of particles at various particle diameters and various air flow rates is shown in Fig. 12. Combination of the spouted situation at various air flow rates can be observed as follows: the small particles whose diameters are smaller than $0.5 \mathrm{~mm}$ can retain an appropriate spouted state only at the air flow rate of $70.4 \mathrm{~m}^{3} / \mathrm{h}$. These particles will be rapidly transported out at a higher air flow rate; Large particles whose diameters are larger than $1 \mathrm{~mm}$ will stay longer in the spray area and maintain spouted state at a lower air flow rate, even though some large particles fall back from the inlet of spray area at $70.4 \mathrm{~m}^{3} / \mathrm{h}$ air flow; The particles whose diameters are between 0.5 to $1 \mathrm{~mm}$ will keep a good spouted state at the air flow rate of $106.2 \mathrm{~m}^{3} / \mathrm{h}$ and pile up at the bottom of the spray area at the air flow rate of $70.4 \mathrm{~m}^{3} / \mathrm{h}$. It will be rapidly transported out of the spray area at the air flow rate of $141.6 \mathrm{~m}^{3} / \mathrm{h}$. For the particles with diameter distribution used in this experiment, it can keep a good spouted transportation state at a certain air flow rate (about $106.2 \mathrm{~m}^{3} / \mathrm{h}$ in this paper). A lower air flow rate will result in particles cannot leave the spray area timely. A higher air flow will result in particles leave the spout area too fast.

Fig. 12 Residence time of particles at various particle diameters and air flow rates

\section{Conclusions}

This paper studied the application of the CPFD method for analyzing dynamic behaviors of multiphase flows in a spouted bed. The impact of pressure, velocity, and concentration were investigated using the CPFD. Physical experiments were used to validate the effectiveness of the simulation results. It provides a reference for the industrial enlargement and control of spouted bed transportation devices. And it also provides a guidance for the balance of pressure parameter and the choice of air and mass flow rate in spouted transportation process. The significantly variable movement and fierce collision of particles at riser after the feed inlet and the outlet of the spray area were well captured by the CPFD simulation. It can found that the pressure drop of the spouted transportation process mainly occurred in these two areas. The results further show that a certain air flow rate exists in order to keep a good spouted transportation state for the particles with various diameter distribution. The particle velocity distribution in the spray area shows that the trend rises in the central region and falls in the region near the wall. Gas flow experiences rapid deceleration after entering into the spray area, and then becomes stable until exiting the spray area. The air flow shows a 
back-mixed movement trend at the top of the spray area. The concentration distribution at the spray area is high near the wall and low in the central region. The spouted transport situations of semi-coke particles in various flow rate were recorded as reference. The consideration of the mass and air flow rate to large scale gas-solid systems in CPFD method better predicted the whole flow characteristics for practical spouted bed

system. Further work will incorporate the simulation of temperature rising in the transportation process in order to investigate the characteristic parameters of oil shale semi-coke combustion.

\section{Acknowledgments}

The authors are grateful for the support of this research by the Program of Changiiang Scholars and Innovative Research Team in University, China (IRT13052), the Natural Science Foundation of Jilin province, China (20150101033JC, and 20150204012SF), the Science and Technology Development Projects of Jilin City, China (201464044), and the Development of Education of Jilin Province, China (2015-237)

\section{References}

[1] C.J. Lim, J.R. Grace. Spouted bed hydrodynamics in a $0.91 \mathrm{~m}$ diameter vessel, Canadian Journal of Chemical Engineering. 65 (1987): 366-372.

[2] M. Olazar, G. Lopez, H. Altzibar, et al. Drying of biomass in a conical spouted bed with different types of internal devices, Drying Technology. 30 (2012): 207-216.

[3] H. Qin, K. Yang, B. Sun, et al. Experimental study on spouted bed hydrodynamics for oil shale semi-coke, Energy Procedia. 17 (2012): 1740-1746.

[4] J. Berghel. The gas-to-particle heat transfer and hydrodynamics in spouted bed drying of sawdust, Drying Technology. 23 (2005): 1027-1041.

[5] M.G. Rasul. Spouted bed combustion of wood charcoal: performance comparison of three different designs, Fuel. 80 (2001): 2189-2191.

[6] Y. He, S. Qin, C.J. Lim, et al. Particle velocity profiles and solid flow patterns in spouted beds, Canadian Journal of Chemical Engineering. 72 (1994): 561-568.

[7] M. Olazar, M. J. S. José, S. Alvarez, et al. Measurement of particle velocities in conical spouted bed using an optical fiber probe, Industrial \& Engineering Chemistry Research. 37 (1998): 4520-4527.

[8] A. Almstedt, V. Zakkay. An investigation of fluidized-bed scaling - capacitance probe measurements in a pressurized fluidized-bed combustor and a cold model bed, Chemical Engineering Science. 45 
(1990): 1071-1078.

[9] M. I. Boulos, B. Waldie. High resolution measurement of particle velocities in a spouted bed using laser-doppler anemometry, Canadian Journal of Chemical Engineering. 64 (1986): 939-943.

[10] J. A. Laverman, I. Roghair, M.V.S. Annaland, et al. Investigation into the hydrodynamics of gas-solid fluidized beds using particle image velocimetry coupled with digital image analysis, Canadian Journal of Chemical Engineering. 86 (2008): 523-535.

[11] X. Zhao, S. Li, G. Liu, et al. Flow patterns of solids in a two-dimensional spouted bed with draft plates: PIV measurement and DEM simulations, Powder Technology. 183 (2008): 79-87.

[12] Y. Lu, L. Qian, W. Zhong, et al. Measurement and uncertainty analysis of the particle phase characteristics in a gas-solid flow, Journal of Engineering Thermophysics. 36 (2015):1481-1486. (In Chinese)

[13] Y. Feng, T. Swenser-Smith, Witt P J, et al. CFD modeling of gas-solid flow in an internally circulating fluidized bed, Powder technology. 219 (2012): 78-85.

[14] V. Taivassalo, S. Kallio, Peltola J. On time-averaged CFD modeling of circulating fluidized beds, International Journal of Nonlinear Sciences and Numerical Simulation, 13 (2012): 363-373.

[15] S. Benyahia, H. Arastoopour, T.M. Knowlton, et al. Simulation of particles and gas flow behavior in the riser section of a circulating fluidized bed using the kinetic theory approach for the particulate phase, Powder Technology. 112 (2000): 24-33.

[16] S. K. Hae, A. Hamid. Simulation of FCC particles flow behavior in a CFB using modified kinetic theory, Canadian Journal of Chemical Engineering. 73 (2009): 603-611.

[17] B. Cha, J. Kim, S. R. Son, et al. CPFD simulation of fluidized bed flow in FCC regenerator, European Symposium on Computer Aided Process Engineering. 30 (2012): 1153-1157.

[18] W. Li, K. Yu, B. Liu,X. Yuan. Computational fluid dynamics simulation of hydrodynamics and chemical reaction in a CFB downer, Powder Technology. 269 (2015): 425-436.

[19] J. M. Weber, J.S. Mei. Bubbling fluidized bed characterization using Electrical Capacitance Volume Tomography (ECVT), Powder Technology. 250 (2013): 138-146.

[20] Q. Wang, H. Yang, P. Wang, et al. Application of CPFD method in the simulation of a circulating fluidized bed with a loop seal, part I-Determination of modeling parameters, Powder Technology. 253 (2014): 814-821.

[21] Q. Wang, H. Yang, P. Wang, et al. Application of CPFD method in the simulation of a circulating fluidized bed with a loop seal Part II-Investigation of solids circulation, Powder Technology. 253 (2014): 822-828.

[22] A. Abbasi, P.E. Ege, H. I. D. Lasa. CPFD simulation of a fast fluidized bed steam coal gasifier feeding section, Chemical Engineering Journal. 174 (2011): 341-350.

[23] F. Fotovat, A. Abbasi, R. J. Spiteri, et al. A CPFD model for a bubbly biomass-sand fluidized bed, Powder Technology. 275 (2015): 39-50. 
[24] Y. Liang, Y. Zhang, T. Li, et al. A critical validation study on CPFD model in simulating gas-solid bubbling fluidized beds, Powder Technology. 263 (2014): 121-134.

[25] Barracuda User Manual. CPFD Software, LLC. US

[26] C. Y. Wen, Y. H. Yu. Mechanics of fluidization. Chem. Eng. Prog. Symp. Ser. 62 (1966): 100-111

[27] C, Chen, J. Werther, S. Heinrich, et al. CPFD simulation of circulating fluidized bed risers. Powder Technology. 235 (2013): 238-247. 